F. Reprod. Fert. (1973) 34, 457-465

\title{
STUDIES ON PROPERTIES OF THE SEMINAL GEL OF THE BOAR USING NATURAL GEL AND GEL FORMED IN VITRO
}

\author{
J. G. BOURSNELL AND E. J. BUTLER \\ A.R.C. Unit of Reproductive Physiology and Biochemistry, Cambridge* \\ and Houghton Poultry Research Station, Houghton, Huntingdon
}

(Received 11th August 1972)

\begin{abstract}
Summary. A method of studying boar seminal gel has been devised which enables investigation to be made on the chemical and physical properties of the gel formed in vitro from the bulbo-urethral (Cowper's) gland mucin and either vesicular secretion or seminal plasma. The majority of the haemagglutinin (protein $\mathrm{H}$ ) in boar vesicular secretion combines with the mucin to form the gel. The content of $\mathrm{Zn}, \mathrm{Mg}$ and citrate of the natural gel is less (often $0.9 \times$ ) than that of the seminal plasma; this ratio also applies to the Kjeldahl $\mathrm{N}$ material imbibed in vitro from seminal plasma or vesicular secretion (as distinct from the $\mathrm{N}$ contributed by the mucin). The imbibed aqueous solution of seminal plasma or vesicular secretion can be defined as 'interstitial' in that its components are diffusible from the gel matrix into buffer. Part of the interstitial water (possibly as much as $10 \%$ ) is 'bound' physicochemically to the gel matrix and is unavailable for solvation of the seminal fluid components.
\end{abstract}

\section{INTRODUGTION}

Seminal gel, which is part of the whole ejaculate of boar semen, originates from a combination of the rubbery mucin (CGM), extruded from the bulbourethral (Cowper's) gland, with vesicular secretion (McKenzie, Miller \& Bauguess, 1938). Involvement with the Proteins $\mathrm{A}$ and $\mathrm{H}$ in this fluid and in seminal plasma was shown by Boursnell, Hartree \& Briggs (1970). If the gel is not separated, it swells by imbibition of fluid, ultimately occupying much of the volume of the total ejaculate. This paper deals with some of the properties of the gel and, more particularly, with the composition of the imbibed fluid in relation to that of vesicular secretion or seminal plasma.

\section{MATERIALS AND METHODS}

\section{Collection of materials}

Seminal plasma and vesicular secretion samples (twenty-one and three,

* Postal address: Animal Research Station, 307 Huntingdon Road, Cambridge CB3 0JQ. 
respectively) were collected from nine boars as described by Boursnell, Baronos, Briggs \& Butler (1972). Four CGM samples were obtained as described by Boursnell et al (1970). Seminal gel was separated about $30 \mathrm{~min}$ after the collection of ejaculates.

\section{Experimental treatment of $C G M$ and gel}

For the experiments, the CGM (and the gel subsequently formed from it in vitro) was held in loops, $3 \mathrm{~mm}$ in diameter, made at the end of 8-cm lengths of enamelled copper wire (26 BSW gauge; $0.45 \mathrm{~mm}$ in diameter).

To make a loop, the pre-weighed wire was threaded through a cut-off surgical needle which acted as a holder for the wire. The projecting end of the wire was looped round a rod of suitable diameter and twisted upon itself (Textfig. 1).

With the loop retained in the holder, portions of the CGM (about $20 \mathrm{mg}$ ) could be scooped up and formed into an adherent mass by dextrous turning of the holder and wire. The CGM and wire were removed from the holder and weighed on a support which avoided contact of the CGM with the balance pan.

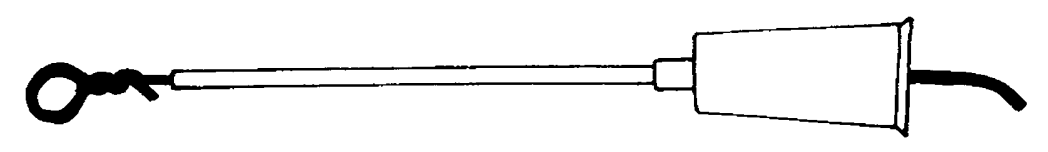

TExT-FIG. 1. Diagram of enamelled copper wire loop held in surgical needle with cut-off tip (scale in $\mathrm{cm}$ ).

Samples (about $100 \mathrm{mg}$ ) of 'natural gel', i.e. gel formed in vivo although the actual formation was not studied, were cut with scissors and impaled on similar pieces of unlooped wire.

With this method, the samples of CGM or gel could be suspended freely in seminal fluid or buffer, avoiding contact with the sides of the vessel. It was often found convenient to use Plasticine (Harbutt's Plasticine Ltd, Bath, England) to fix the free upper end of the wire without movement.

Immersion of the CGM in seminal plasma or vesicular secretion caused the formation of the gel which adhered to the loop, making it possible to carry out analyses on known weights of the CGM or gel treated in various ways, e.g. by washing in buffers. The weight of the gel still attached to the wire was determined after quickly blotting on filter paper. The free fluid was easily removed and further weight loss was negligible in the interval required for weighing. Kjeldahl $\mathrm{N}$ determinations as described by Boursnell et al. (1970) could be carried out with about $1 \mathrm{~cm}$ of the wire still attached to the CGM or gel. The $\mathrm{N}$ content of the interstitial fluids (as defined in this work) could be determined by subtracting the $\mathrm{N}$ value calculated for $20 \mathrm{mg}$ CGM from the $\mathrm{N}$ value of the gel formed in vitro, also corrected to $20 \mathrm{mg}$ initial weight of CGM. A similar but not identical value could be derived by multiplying the weight increase by the $\mathrm{N}$ value of the seminal fluid used. 
Buffers

The buffers used for washing were, except where otherwise indicated, at $\mathrm{pH} 7$, $I=0.3$ (Miller \& Golder, 1950).

\section{Determinations of substances}

Haemagglutinin titration of protein $\mathrm{H}$ followed the method of Boursnell (1967), using sheep red cells. Zinc, calcium and magnesium were determined by atomic absorption after dry ashing or by the Kjeldahl method (for $\mathrm{Zn}$ ) as described by Boursnell et al. (1972). Ergothioneine was determined by Mann's (1964) modification of Hunter's (1949) method, and citrate by the method of Speck, Moulder \& Evans (1946) as modified by Mann, Davies \& Humphrey (1949).

\section{RESULTS}

Effect of dialysis of vesicular secretion on gel formation

Gel formation from CGM was studied with (1) native vesicular secretion, (2) $2 \mathrm{ml}$ vesicular secretion dialysed against $200 \mathrm{ml}$ buffer and (3) a small volume $(4 \mathrm{ml})$ of buffer which had been used to dialyse $2 \mathrm{ml}$ vesicular secretion. Normal gels formed in the first two cases but in the third, a sticky, rather runny gel was formed.

\section{Weight and nitrogen gain during formation of gel}

Treatment of CGM for $24 \mathrm{hr}$ with vesicular secretion or seminal plasma caused rather similar mean weight gains (e.g. vesicular secretion, $4 \cdot 8 \times \pm 0 \cdot 17$ S.E.M.; seminal plasma, $5 \cdot 6 \times \pm 0 \cdot 12$ S.E.M.). In another experiment with different samples, the mean weight gains after $22 \mathrm{hr}$ were $4.92 \times$ (vesicular secretion) and $5.40 \times$ (seminal plasma); a further $8 \%$ was gained by both after $22 \mathrm{hr}$ subsequently in buffer. These experiments showed an interstitial $\mathrm{N}$ concentration about 80 to $90 \%$ of that of the treating seminal fluid. Rapid loss of $\mathrm{N}$ occurred when gels formed in vitro were washed in buffer; typically, $19 \%$ was lost in $10 \mathrm{~min}$ and $33 \%$ in $2 \mathrm{hr}$. Further $\mathrm{N}$ loss was small; at $24 \mathrm{hr}$, it was not significantly different from that at $3 \mathrm{hr}$ (comparable $\mathrm{N}$ losses $-38 \%$ in $22 \mathrm{hr}-$ were encountered when natural gel samples were similarly washed).

The stable $\mathrm{N}$ values in the in-vitro experiments were, after dialysis, greater than the GGM $\mathrm{N}$ alone. Loss of $\mathrm{N}$ was not due to a dialysable $\mathrm{N}$ compound (e.g. a polypeptide) released by the formation of the gel; no $\mathrm{N}$ was lost on dialysis of gel formed from already dialysed seminal plasma and CGM when these were subsequently combined inside a cellophane sac.

The weight gain of CGM samples in seminal plasma was followed at short intervals $(10 \mathrm{~min})$ and related to the increase in the total and interstitial $\mathrm{N}$ of the gel. The N per unit weight of the gel (total and interstitial) remained substantially constant in spite of a curvilinear weight increase to $2.9 \times$ that of the initial CGM. After $1 \mathrm{hr}$, neither the weight increase nor the $\mathrm{N}$ gain had apparently ceased. The ratio of observed $\mathrm{N}$ to 'seminal plasma $\mathrm{N}$ plus CGM N' was constant $(0.96 \pm 0.01$ S.E.M.) throughout. Samples of CGM were treated with seminal plasma for even shorter intervals $(10 \mathrm{sec}, 20 \mathrm{sec}$, and 1, 5 and 10 
$\min$ ) and analysed for $\mathrm{N}$ with or without a period ( $24 \mathrm{hr}$ ) in buffer. Untreated CGM dispersed in buffer but CGM samples treated with seminal plasma, even for $10 \mathrm{sec}$, were frail but manageable. With increasing time, firmer gels resulted. In no case was interstitial $\mathrm{N}$ detected although the weight gain was about $2 \times$ in all, rising to $6 \%$ in the buffer. At periods up to $1 \mathrm{~min}$, the $\mathrm{N}$ values of the gel formed were less (about 13\%) than those of the untreated CGM; the frail gels were seen to lose uncombined CGM during transfer. Buffer washing removed N

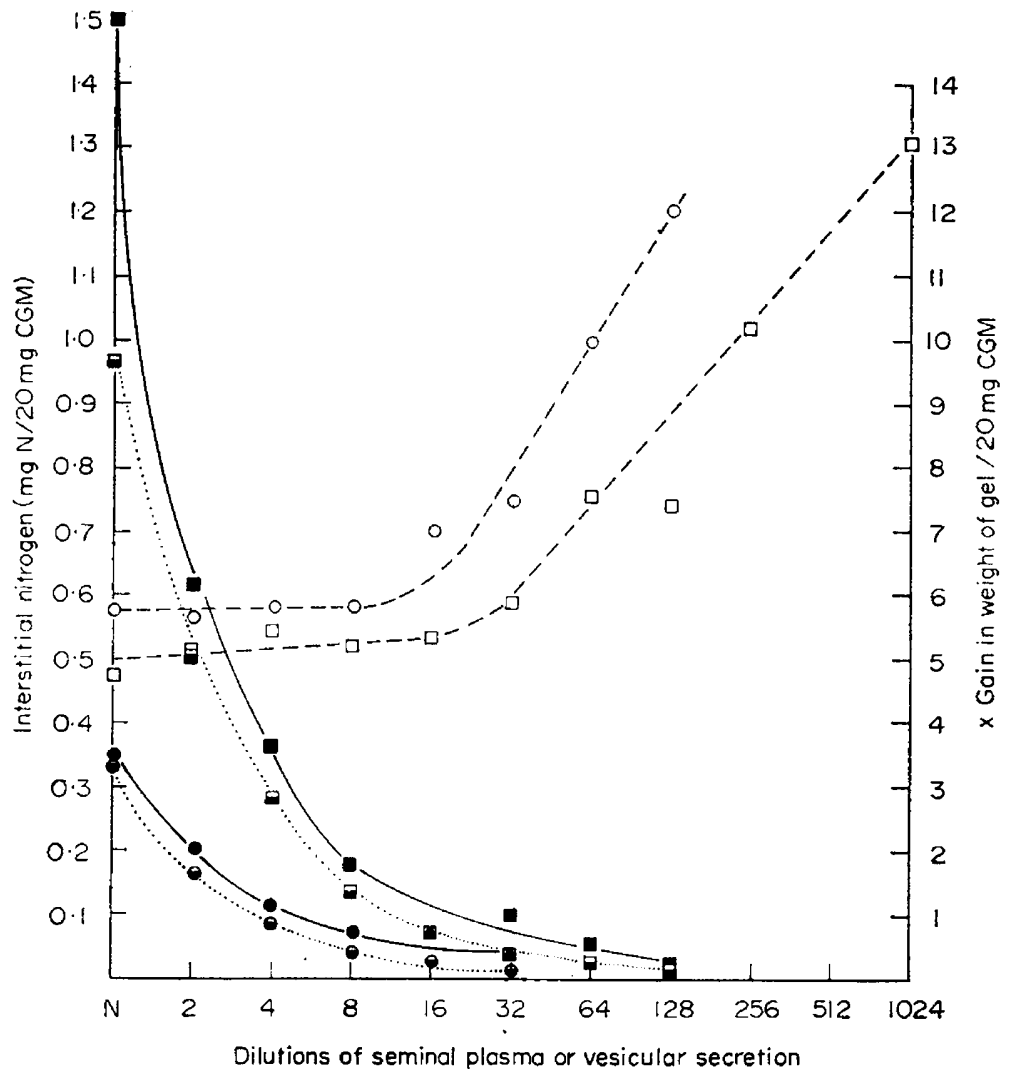

TeXT-FIG. 2. Interstitial nitrogen (-) and gain in weight of gel (--) per $20 \mathrm{mg}$ initial Cowper's gland mucin (CGM) after its treatment with doubling dilutions of boar seminal plasma ( $O$ and $\bullet$ ) or boar vesicular secretion ( $\square$ and $\square)$. $(\mathbf{N}=$ neat seminal fluid). $\cdots \cdots \cdots$, Alternative calculations (per $20 \mathrm{mg}$ initial GGM) of 'interstitial' nitrogen from corresponding seminal plasma or vesicular secretion nitrogen values multiplied by (gain in weight -1 ).

from the samples which had short treatment times (49\% at $10 \mathrm{sec}, 74 \%$ at $30 \mathrm{sec}$ and $72 \%$ at $1 \mathrm{~min}$ ) but at 5 and $10 \mathrm{~min}$, the loss was negligible. Gel formed in vitro, with properties resembling the naturally formed gel, took several minutes to mature at room temperature $\left(19^{\circ} \mathrm{C}\right)$.

\section{Effect of dilution of seminal plasma and vesicular secretion}

Serial doubling dilutions in buffer of $2 \mathrm{ml}$ seminal plasma $(3.46 \mathrm{mg} \mathrm{N} / \mathrm{ml})$ and vesicular secretion $(12.8 \mathrm{mg} \mathrm{N} / \mathrm{ml}$, i.e. $3.7 \times$ the seminal plasma concentration) 
were used to form gels from CGM. After $23 \mathrm{hr}$, although a looser gel was formed at the higher dilutions, it was possible to examine (Text-fig. 2) the gain in weight at dilutions of $1 / 128$ with seminal plasma and 1/1024 with vesicular secretion. This gain was almost constant (about $5 \times$ ) up to $1 / 8$ (seminal plasma) and $1 / 32$ (vesicular secretion), i.e. at similar seminal fluid $N$ values (about 0.4 $\mathrm{mg} \mathrm{N} / \mathrm{ml}$ ). Beyond this dilution, a sharp, approximately linear, increase occurred.

The difference between interstitial $\mathrm{N}$ and the $\mathrm{N}$ content of the corresponding diluted seminal fluids was relatively constant (seminal plasma, neat to $1 / 32$, mean $=0.030 \pm 0.005$ S.E.M.; vesicular secretion, $1 / 4$ to $1 / 128$, mean $=$ $0.041 \pm 0.01$ S.E.M.).

\section{Effect of gel formation on haemagglutinin titre of seminal plasma}

The haemagglutinating titre of $0.3-\mathrm{ml}$ quantities of seminal plasma was reduced from 4096 to 512 by a 4 -hr immersion of a CGM sample in each. This represents an eightfold reduction in the haemagglutinin, but the gel only absorbed about $20 \%$ (mean $59 \mathrm{mg}$ ) of fluid from the seminal plasma. Interstitial $\mathrm{N}$ was $90 \%$ of the seminal plasma value, and $45 \%$ of this was removed by washing in $0.3 \mathrm{ml}$ buffer. The resulting titre of this buffer (128, or one quarter of the treated seminal plasma) is consonant with the $1 / 6$ dilution (59 $\mathrm{mg}$ diffused into $300 \mathrm{mg}$ buffer) of the free interstitial seminal plasma.

\section{Effect of temperature on gel formation}

The effect of temperature on gel formation was studied when CGM samples were immersed for $1 \mathrm{hr}$ in $2 \mathrm{ml}$ vesicular secretion at $4^{\circ}, 19^{\circ}$ and $37^{\circ} \mathrm{C}$. The weight gain increased with temperature: at $4^{\circ} \mathrm{C}, 1.9 \times$; at $19^{\circ} \mathrm{C}, 2.3 \times$; at $37^{\circ} \mathrm{C}, 3 \cdot 1 \times$. After washing for $2 \mathrm{hr}$ with $200 \mathrm{ml}$ buffer at $19^{\circ} \mathrm{C}$, the gain further increased: at $4^{\circ} \mathrm{C}, 3.0 \times$; at $19^{\circ} \mathrm{C}, 3.3 \times$; at $37^{\circ} \mathrm{C}, 3.6 \times$. Interstitial $\mathrm{N}(\mathrm{mg} / \mathrm{ml})$ also rose with temperature : at $4^{\circ} \mathrm{C}, 0.204$; at $19^{\circ} \mathrm{C}, 0.298$; at $37^{\circ} \mathrm{C}$, 0.524 . This increase was evident even when allowance was made for the extra weight gained at $19^{\circ} \mathrm{C}$ and $37^{\circ} \mathrm{C}$ relative to that at $4^{\circ} \mathrm{C}$ : at $4^{\circ} \mathrm{C}, 0.204$ (as above); at $19^{\circ} \mathrm{C}, 0.251$; at $37^{\circ} \mathrm{C}, 0.328$. Washing showed that the increased $\mathrm{N}$ (again adjusted to constant weight gain) was 'fixed', the amounts lost being substantially constant at all temperatures: at $4^{\circ} \mathrm{C}, 0 \cdot 189$; at $19^{\circ} \mathrm{C}, 0.210$; at $37^{\circ} \mathrm{C}, 0 \cdot 184$. At all temperatures, the concentration of interstitial $\mathrm{N}$ (mean $12.0 \pm 0.6$ S.E.M.) represents about $90 \%$ of the vesicular secretion value.

\section{Influence of ionic strength}

The influence of ionic strength $(I)$ of the buffer was studied when samples of gel formed in vitro were washed in buffers at seven values of $I$ from 0.2 to 0.5 , inclusive. Both the mean weight gain $(5.58 \times \pm 0.11$ S.E.M.) and the interstitial N remaining $(31.9 \% \pm 4 \cdot 1$ S.E.M. calculated on the seminal plasma value) were constant at all values of $I$.

\section{Distribution of seminal zinc in gel, seminal plasma and spermatozoa}

The distribution of zinc between seminal plasma, spermatozoa and gel was studied in three ejaculates. After determination of the weights or volumes of the 


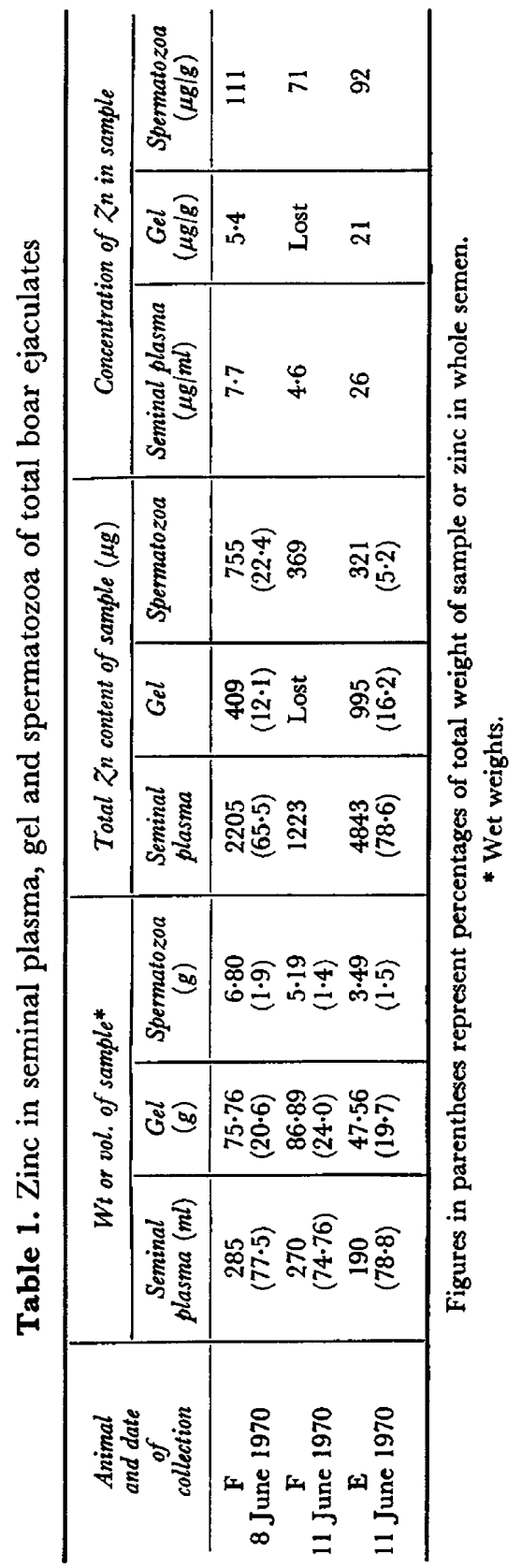


entire phases, they were separately freeze-dried. The products were weighed, triturated and equilibrated to air humidity. Weighed samples were analysed for $\mathrm{Zn}$ (Table 1). The zinc concentrations in the two available gels were 70 and $81 \%$ of the corresponding seminal plasma values; other direct comparisons of $\mathrm{Zn}$ between natural gel and seminal plasma samples gave values of $79 \%$ and $57 \%$. Magnesium ( $86 \%$ and $88 \%$ ) behaved similarly, but the Ca values considerably exceeded (about 2.5 to $4 \times$ ) those of the homologous seminal plasma samples: Ca values found in CGM samples were very high (mean, $360 \mu \mathrm{g} / \mathrm{g}$ wet weight).

Dialysis of 4-g samples of natural gel at $4^{\circ} \mathrm{C}$ in buffer at $\mathrm{pH} 5$ slowly removed zinc ( $79 \%$ at $48 \mathrm{hr} ; 92 \%$ at $96 \mathrm{hr}$ ). The resulting gels were as opalescent as the in-vitro preparations. In other experiments at $\mathrm{pH} \mathrm{6,7}$ and 8, the amount of zinc removed appeared to lessen with increasing $\mathrm{pH}$.

Citrate, found in $15 \%(\mathrm{w} / \mathrm{v})$ trichloroacetic acid in which weighed samples of natural gel from two whole ejaculates had been immersed for $12 \mathrm{hr}$ at $19^{\circ} \mathrm{C}$, corresponded to $70 \%$ and $51 \%$ of that in the homologous seminal plasma. In other experiments, both citrate and ergothioneine were found to be readily diffusable from natural gel into buffer at $\mathrm{pH} 7$.

\section{DISCUSSION}

The formation of the gel from CGM, incorporating much of the Protein $\mathrm{H}$ in vesicular secretion, is a process which takes some time to mature. Boursnell et al. (1970) showed that, with $5 \%(\mathrm{w} / \mathrm{v})$ solutions of CGM, initial gel setting was very fast, but this is probably an initial stage in a process which is only completed after some time. The formed gel imbibes seminal plasma or vesicular secretion components, some of which reflect the composition of the seminal fluid and are diffusable into a buffer. Slow maturation of the gel may be due to slow diffusion of these components through the partly formed matrix of the primary gel. With increasing temperature, more N-containing material becomes fixed in the gel structure and is non-diffusable. With more dilute seminal plasma or vesicular secretion (protein $\mathrm{N}$ about $0.4 \mathrm{mg} / \mathrm{ml}$ ), a probable structural change results in a weakened gel. The partial formation of the gel with the buffer used for dialysing the vesicular secretion suggests a similarity to the ultrafiltrate, containing traces of Protein A but not the haemagglutinin, described by Lavon, Boursnell \& Briggs (1972) and Boursnell, Briggs, Lavon \& Butler (1973).

The interstitial composition of the gel formed in vitro appears to be akin to the naturally formed material, although the latter exhibits spherical discontinuities within the round aggregates. These appear to be slowly eliminated by further swelling in buffer, resulting in an opalescent homogenous gel resembling the material formed in vitro.

The non-dialysable $\mathrm{N}$ values in the experiments carried out in vitro were greater than the CGM alone and this suggests that, in addition to loosely held interstitial nitrogenous components, there was a 'fixed' part incorporated more closely into the gel molecular structure. It was shown that the loss of Protein $\mathrm{H}$ was due to its selective incorporation into the matrix of the gel as a fixed part of the interstitial $\mathrm{N}$ as defined above. Once fully formed, the continued presence 
of the gel in semen did not alter the titre of seminal plasma samples separated at intervals (Boursnell, 1967).

Part of the purpose of this work was to discover if the gel specifically incorporated Protein $\mathrm{H}$ and $\mathrm{Zn}$. The ratio of the concentrations of these two substances in seminal plasma and vesicular secretion was lower than with other materials (about 0.2) examined by Mann \& Glover (1954): the haemagglutinin titre of seminal plasma is often five tubes lower than that of vesicular secretion, representing a 32 -fold dilution (i.e. $2^{-5}$ ): the zinc ratio, taken from the mean figures given by Boursnell et al. (1972), is 0.165. It was shown that the loss of Protein $\mathrm{H}$ is due to its incorporation into the gel structure. The $\mathrm{Zn}$ was not thus incorporated, but the high $\mathrm{Zn}$ values in spermatozoa suggest that part at least may be absorbed from the vesicular secretion and this aspect is being investigated.

The values for Ca in CGM found in this work are greatly in excess of the low $\mathrm{Zn}$ values reported by Boursnell et al. (1972) and could account for almost all the extra $\mathrm{Ca}$ concentration encountered in the gel compared with the homologous seminal plasma. This $\mathrm{Ca}$ may help to neutralize the sialyl residues in GGM (Hartree, 1962).

In many cases in this work, nitrogen and other values for interstitial fluid were about 80 to $90 \%$ of that of the corresponding seminal fluids. It is suggested that part of the reason for these low values may be due to the presence of 'bound' or 'combined' water in the gel, unavailable for dissolving solutes (Moran, 1932).

\section{ACKNOWLEDGMENTS}

We would like to thank Miss L. D. Stone in particular for working out the in-vitro method and for all the $\mathrm{N}$ determinations. We are grateful to other colleagues for their specific help: Miss P. A. Briggs (haemagglutinin and ergothioneine), Miss G. A. Reynolds (citrate) and Mrs G. K. Foreman (Zn, Ca and $\mathrm{Mg}$ ).

\section{REFERENGES}

BoURSNELL, J. C. (1967) Boar seminal haemagglutinin. 2. Combination with red cells and spermatozoa. J. Reprod. Fert. 13, 297.

Boursnell, J. C., Baronos, S., Briggs, P. A. \& Butler, E. J. (1972) The concentrations of zinc in boar seminal plasma and vesicular secretion in relation to those of nitrogenous substances, citrate, galactose and fructose. 7. Reprod. Fert. 29, 215.

Boursnell, J. G., Briggs, P. A., LAvon, U. \& Butler, E. J. (1973) The association of zinc with some components of boar vesicular secretion and seminal plasma. II. Ultrafiltration and ethanolprecipitation studies. F. Reprod. Fert. 34, 73.

Boursnele, J. C., Hartree, E. F. \& Briggs, P. A. (1970) Studies on the bulbo-urethral (Cowper's) gland mucin and seminal gel of the boar. Biochem. F. 117, 981 .

HARTREe, E. F. (1962) Sialic acid in the bulbo-urethral glands of the boar. Nature, Lond. 196, 483.

Hunter, G. (1949) The determination of ergothioneine in simple solution and in blood. Can. F. Res. 27E, 230.

Lavon, U., Boursnell, J. G. \& Briggs, P. A. (1972) Further characterization of the proteins of boar seminal plasma by isoelectric focusing on polyacrylamide. F. Reprod. Fert. 30, 165.

MaKenzie, F. F., Miller, J. C. \& Bauguess, L. C. (1938) The reproductive organs and semen of the boar Res. Bull. Mo. agric. Exp. Sin, 279.

MANN, T. (1964) The biochemistry of semen and of the male reproductive tract. Methuen, London. 
MANN, T., DAviss, D. V. \& Humphrey, G. F. (1949) Fructose and citric acid assay in the secretions of the accessory glands of reproduction as indicator tests of male sex hormone activity. F. Endocr. 6,75 .

MANN, T. \& Glover, T. (1954) Contribution of the seminal vesicle towards the composition of whole semen. F. Endocr. 10, iv.

Miller, G. L. \& Golder, R. H. (1950) Buffers of pH 2 to 12 for use in electrophoresis. Archs Biochem. $29,420$.

Moran, T. (1932) The hydration or combined water of gelatin. Proc. R. Soc. A, 135, 411.

SPECK, J. F., Moulder, J. W. \& Evans, E. A. (1946) The biochemistry of the malaria parasite. 5. Mechanism of pyruvate oxidation in the malaria parasite. F. biol. Chem. 164, 119. 